\title{
Conversas precisamente incertas com Kuniichi Uno
}

\author{
Joana Camelier ${ }^{\star}$ \\ Universidade Federal Fluminense, Niterói, RJ, Brasil
}

Resumo

\begin{abstract}
O artigo trata de conversas com o filósofo japonês Kuniichi Uno a respeito de seu trabalho e de sua pesquisa sobre as delineações do corpo na dança e na filosofia. As conversas foram feitas presencialmente e por mensagens eletrônicas, de modo que sua apresentação abrange temporalidades e meios de comunicação distintos. Isto faz delas antes uma experiência que propriamente uma entrevista. São levantadas sobretudo questões referentes à força de gênese do corpo, tema que Uno trabalha em seu livro A gênese de um corpo desconhecido, publicado no Brasil em 2012.
\end{abstract}

Palavras-chave: corpo; força; tempo; corpo-sem-órgãos.

\section{Precisely uncertain conversations with Kuniichi Uno}

\begin{abstract}
The article is about conversations with the Japanese philosopher Kuniichi Uno regarding his work and his research on the delineations of the body in dance and philosophy. The conversations were made in person and by electronic messages, so its presentation encompasses different temporalities and means of communication. This makes them an experience rather than an interview. The questions raised are particularly referred to the force of genesis of the body, a theme that Uno works on in his book The genesis of an unknown body, published in Brazil in 2012.
\end{abstract}

Keywords: body; force; time; body without organs.

Kuniichi Uno nasceu no Japão em 1948 e é professor na Universidade de Rikkyo, em Tóquio. Fez seu doutorado na França, sob a orientação de Gilles Deleuze, com uma tese sobre Antonin Artaud. Esse e outros entrelaçamentos do pensador - que tem uma vasta pesquisa sobre dançarinos de butô (notadamente Min Tanaka e Tatsumi Hijikata) - evidenciam sua sensibilidade e interesse pelo tema do corpo. Em português, temos a compilação de alguns preciosos artigos seus reunidos no livro $A$ gênese de um corpo desconhecido (UNO, 2012), que é uma inspiração para tantos de nós pesquisadores do Laboratório de Subjetividade e Corporeidade - Corporeilabs. Foi tocada por essa inspiração, que vi a possibilidade de ter uma conversa com Kuniichi, quando ele esteve no Brasil em outubro de 2016. No Rio de Janeiro, ele deu uma palestra no Ciclo "O ato criador", no Oi Futuro Ipanema; e em São Paulo, fez o lançamento do livro de entrevistas Guattari confrontações (UNO, 2016) no qual constam duas entrevistas suas e uma de Laymert Garcia dos Santos com Félix Guattari. Kuniichi Uno é ainda tradutor para o japonês das principais obras de Deleuze e Guattari, de Foucault, de Artaud e de Becket, o que faz dele um interlocutor próximo às questões que na UFF chamamos de transdisciplinares à clínica. Na direção apontada por tal proposta, trabalhar os domínios transdisciplinarmente vai além da colaboração entre eles, pois acaba por gerar um pensamento organizador que os ultrapassa. Dessa forma, outros campos de saber como a filosofia, a política, a arte, etc. são convocados à composição com a clínica (PASSOS; BARROS, 2000, 2003; RAUTER, 2013).

Essas conversas com Kuniichi aconteceram presencialmente e por trocas de mensagens eletrônicas, que temos mantido desde que nos conhecemos no Rio em

\footnotetext{
^Endereço para correspondência: Universidade Federal Fluminense, Instituto de Psicologia, Programa de Pós-Graduação em Psicologia. Campus do Gragoatá Rua Prof. Marcos Waldemar de Freitas Reis, s/n, Bloco N, Sala 413 Gragoat - Niterói - RJ - Brasil. CEP: 24210-201.E-mail: joanacamelier@gmail.com
}

2016. Estas só podem ser descritas desse modo, como o/a leitor/a verá, envolvendo uma profusão de tempos e de meios, porque se trata antes de uma experiência do que de um diálogo direto. Experiência esta, que deve levar em conta uma brasileira e um japonês, comunicando-se numa língua terceira, o francês. Kuniichi tem o tom de voz baixo, polido, e às perguntas feitas por mim ele tomava um tempo antes de responder. Parecia-me que seu pensamento vagava entre milhares de possíveis antes que ele se arriscasse a traçar um caminho plausível de ser enunciado. Houve pausas e frases inconclusas, porque - imagino eu - ele de fato se aventurava a pensar algo diferente, ou ao menos a dizer de forma diferente. $\mathrm{O}$ dia a dia na clínica confere essa capacidade de perceber um pensamento efetivamente em vias de criação e enunciação, e foi exatamente isso o que vi acontecer em um de nossos encontros, que se deu no jardim do Palácio do Catete, onde fica o Museu da República. Fizemos um passeio e pude contar um pouco sobre este local que tem uma importância histórica para nós, brasileiros, pois foi sede de nosso poder executivo de 1897 a 1960 (ele voltou sozinho novamente ao jardim, no dia seguinte, para tomar um café).

Enfatizo outra vez que essas conversas são mais da ordem de uma experiência, porque me evocaram empiricamente algo que li em Roland Barthes há anos atrás a respeito do Japão e dos japoneses em seu livro $O$ império dos signos:

Não é a voz (com a qual identificamos os "direitos" da pessoa) que comunica (comunicar o quê? nossa alma - forçosamente bela - nossa sinceridade, nosso prestígio?), é o corpo todo (os olhos, o sorriso, a mecha, o gesto, a roupa) que mantém conosco uma espécie de balbucio, ao qual o perfeito domínio dos códigos tira todo caráter regressivo, infantil. Marcar um encontro (por gestos, desenhos, nomes próprios) leva de fato uma hora, mas durante essa hora, para uma mensagem que se teria abolido num instante se tivesse 
sido falada (ao mesmo tempo essencial e insignificante), é o corpo todo do outro que é conhecido, degustado, recebido, e que desenvolveu (sem verdadeira finalidade) sua própria narrativa, seu próprio texto (BARTHES, 2007, p. 18).

Deste modo, só se pode conceber essas trocas que fiz com Kuniichi sob uma perspectiva sensível: há de se invocar a porosidade do corpo e também a do pensamento para perceber nuances que estão aquém e além do que é dito - estão no modo como é dito, mas também naquilo que não é dito (e aqui a proximidade com o tema do Dossiê Corporeidade e com as pesquisas do Corporeilabs é evidente). Silêncios, pausas, hesitações, pequenos sorrisos e um mundo de sentidos que os povoam. Guattari ${ }^{1}$ já entrevera uma espécie de afinidade inconsciente e secreta entre o Brasil e o Japão e talvez seja disso mesmo que se trata.

Uma das questões que mais me chamou a atenção no livro A gênese de um corpo desconhecido está contida em apenas um parágrafo, do qual retiro uma frase para começar minha conversa com Kuniichi: "no fundo, a vida e o corpo nada mais são que a mesma coisa, mas, para que sejam verdadeiramente o mesmo e o corpo seja digno da vida, será preciso descobri-lo em sua própria força de gênese, em seu tempo próprio" (UNO, 2012, p. 66). Pergunto-lhe: do que se trata essa força? Quais são os meios pelos quais podemos acessá-la ou evocá-la?

Kuniichi me escreve:

A questão da força, ou das forças (como ela é sempre múltipla), eu a coloco sempre de partida junto àquela da diferença da força natural e da força humana, social, que se define mais como "poder". A força ou a violência natural do vulcão, da tempestade, pode ser terrivel, mas no fundo, a força da vida, da vitalidade, é da mesma natureza, pode ser esplêndida, terrivel, mas inquietante.

Quando a força (natural) é manipulada, dirigida, disfarçada pela humanidade, o governo, o rei, o exército, etc. ela pode se tornar uma violência brutal insuportável. Isso todo mundo sabe.

Porém, o que complica o problema da força, é que ela vai para toda parte e sem forma, frequentemente invisivel, imensurável. O corpo é um solo importante sobre o qual as forças se centram, se entrecruzam, se transbordam... Sem dúvida há sempre técnicas do corpo para controlar todos esses movimentos de forças que podem ser terrivelmente perigosos, mas criadores e eufóricos também.

A força é sem forma. As máquinas artificiais podem controlar as forças de maneiras muito sofisticadas, mas a força humana, social, mental, emocional, não se sabe nunca como totalmente controlá-la. Spinoza parece muito sensivel a esse problema... nossa razão não é suficiente para controlá-la porque a razão é ela mesma fundada sobre as forças.

Ai há verdadeiramente a questão: como acessar essa força. Uma arte é uma possibilidade de operar o que não é operável, uma análise (filosófica, ou psicológica no sentido global) pode ser também um dispositivo para operar as forças.

${ }^{1}$ Entrevista a Kuniichi Uno em 20 janeiro de 1992 (cf. UNO, 2016, p. 101-140).
O teatro da crueldade (Artaud) coloca precisamente esse problema: como acessar essas forças cruéis, porque o desafio do teatro é a crueldade da força - como acolhê-la e se defender dela também.

É no livro Lógica da sensação ${ }^{2}$ que Deleuze fala exatamente como "pintar a força" e coloca a questão da força como aquela que ultrapassa a dimensão da fenomenologia.

Eu gostaria de me explicar de maneira mais concreta e nuançada, sobretudo sobre Artaud, citando seus textos poéticos, mas em outra ocasião. Eu tive uma visão concreta do problema da força lendo os textos de Artaud, aquilo que se encontra no Pesa-nervos, ${ }^{3}$ etc.

Volto aos registros de nosso encontro no Rio, quando havia feito a mesma pergunta a ele, para resgatar seus comentários naquela ocasião. Eis seu pensamento se fazendo:

Isso é complicado... O que é essa força? Antes de tudo eu pensaria que é a força da vida. A vida é uma força, para viver deve haver uma força, mas para ter a força deve haver uma vida também. A vida é uma energia. Qual é a diferença entre a energia e a força? Pode-se definir em termos científicos, mas não estou certo de que seria o caminho...

Quando eu falo de força, nesse contexto, penso a vida sendo igual talvez a certo tipo de força. E depois, bom, por que o problema da força é tão complicado? Porque a questão da força envolve todo um sistema de disfarce, de desvio.

Quando se fala de poder, estamos já num lugar político. O poder é um sistema de forças, uma forma de forças sistematizadas, são forças formalizadas. Enquanto a força da vida, para mim, biologicamente, não tem nada de misterioso. Contudo, a força é qualquer coisa de indefinivel, de desconhecida. E o poder já é uma espécie de organização, uma codificação das forças. Um processo de fechamento e de cerceamento das forças.

A diferença entre a força e o poder é algo muito importante e complicado. Nietzsche coloca o problema da vontade de poder, que é naturalmente um problema da vontade de força. Então há uma sociedade, há todas as formas de poder e de forças deformadas e desviadas. Deleuze e Nietzsche colocam o problema da diferença entre a força ativa e a força reativa. A força reativa cria ou fabrica outra dimensão da força para a humanidade, o que concerne também qualquer coisa de psicológico. Porque na psicologia existe todo um sistema ou um modo de desvio da força, o que tem a ver com todas as formas de ressentimento $e$ reação. Em um sentido é quase uma criação ou invenção em si mesma: o ciúme, a tristeza, a cólera, há um drama e uma teatralização da psyché.

Nietzsche vindo à conversa me lembrou da surpresa que tive ao ler na entrevista de Kuniichi com Guattari ${ }^{4}$ que este último não gostava das ideias do filósofo alemão e rejeita o conceito de força. Kuniichi o interpela a respeito do trabalho realizado com Deleuze em O Anti-Édipo e Mil platôs (DELEUZE; GUATTARI, 1995a, 1995b, 1996, 1997a, 1997b, 2010), nos quais enxerga um tipo de filo-

\footnotetext{
${ }^{2}$ Deleuze (2007).

${ }^{3}$ Artaud (1995).

${ }^{4}$ Entrevista a Kuniichi Uno em 30 de março de 1984 (UNO, 2016, p. 43-98).
} 
sofia da força e filosofia do corpo. A questão lhe é cara, uma vez que o conceito de "corpo-sem-órgãos" advém de Artaud e traz a questão das intensidades que ultrapassam o corpo orgânico - tema que aparece diversas vezes em seus escritos sobre os dançarinos de butô. Contudo, Guattari é enfático ao afirmar que falar de forças é problemático, pois levanta uma questão dialética e conflituosa da subjetividade determinada por instâncias topicamente distintas. Seria preciso, segundo este último, inventar um modo novo de falar para escapar à herança semântica já fortemente constituída de tudo o que envolve o termo "força" (sentidos dinâmicos, energéticos, físicos, temporais, etc.).

Minha curiosidade se volta então para Kuniichi: "para mim foi uma surpresa saber o que Guattari pensava sobre a filosofia da força. Neste caso, que ele não gostava desse termo e que não estava de acordo com seu uso. Você compreende o que ele quis dizer? Porque eu faço uma leitura dessa questão das forças que, penso, é similar à sua..."

Você faz bem em evocar o que Guattari disse na nossa conversa sobre o problema da força: ele exprimiu uma espécie de desconfiança profunda no termo da "força" e é verdade que isso também me surpreendeu durante a entrevista.

Sobretudo o problema da força na dimensão politica. Há qualquer coisa de embaraçoso na maneira em que colocamos o problema da força, principalmente quando dizemos que tudo gira em torno das forças como se fosse uma realidade absoluta, inegável. Sobre o plano politico, toda força se efetua com a fala, as palavras de ordem. As forças ou as violências mais temíveis são realizadas e mobilizadas por decisões ou instruções verbais, que não são, em si mesmas, nem a força nem a violência.

Guattari fala de Alice no país das maravilhas, Alice só existe em uma pura dimensão de linguagem, de fala, de "sentido". É curioso que Guattari seja tão favorável à Lógica do Sentido ${ }^{5}$ nesse ponto de vista. Ele insistiu bastante, em seu pensamento após o período de sua colaboração com Deleuze, sobre as partículas-signos ou o incorporal como qualquer coisa que pode provocar uma profunda mutação das coisas.

De todo modo, o problema da força e das naturezas diferentes da força existe, mas não há nunca o problema puro da força, porque o pensamento e o corpo são já trabalhados pelas forças múltiplas em variação - e assim, forças já afetadas pelas dimensões sociais, psicológicas, linguageiras, etc.

O que Kuniichi explica ainda sobre esta questão é que não há sujeito, e menos ainda um sujeito que "tenha" a força. Existe, sim, uma posição de desejo que muda a todo o tempo e que muda de relação também.

Não há nada de substancial... Os termos, as palavras... Por exemplo, a diferença de um cachorro-cachorro, de um cachorro-gato, de um cachorro-tigre, cavalo, etc. é que não há cavalo, gato, para o cachorro. Há apenas a diferença, então a questão é somente a distribuição de termos e a relação entre eles que conta. Não existe um cachorro que tenha uma força especial.

${ }^{5}$ Deleuze (1988).

Fractal, Rev. Psicol., v. 29 - n. 2, p. 219-222, 2017
Se não há nunca o problema da força pura, “em si”, só podemos percebê-la no encontro (ou mesmo no embate) com outras forças. Existem, então, as coisas que escapam ao bloqueio que se exerce sobre a vida, não?

Dentro de um conjunto há sempre um sistema majoritário, também um poder majoritário, que codifica, que ordena todas as forças e as relações de força. E há sempre as fugas ao sistema. Por exemplo, uma criança antes de ser codificada, antes de ser desviada. Em relação ao sistema masculino, a feminilidade é em qualquer parte uma linha de fuga. Essas formas bastante variadas mostram que a força da vida se exprime sempre ao longo de um atraso deste sistema.

Os entremeios dos jogos de forças estão sempre se dando...

Bom, já falamos da força, a força é a vida. É o problema da vida, da vitalidade. E é a vida também que cria esses desvios. A vida deve ser desviada, a vida deve até mesmo ser diminuida. É como se tivéssemos ao mesmo tempo necessidade da vida e de qualquer coisa que impeça a vida, que a bloqueie. Tem sempre esse jogo na nossa sociedade e mesmo na nossa psicologia.

Nas conversas que estamos mantendo por correio eletrônico, conto um pouco para Kuniichi como a tarefa da escrita da tese tem sido difícil, para não dizer impossível, o que me causa muita angústia. Pensar e escrever na fronteira em que o corpo força o pensamento ao limite, longe o suficiente para que ainda seja pensamento, mas nunca o bastante para que possamos afirmar que é o mesmo que o corpo.

Ele diz que "é preciso achar e afirmar um modo de falar daquilo que é "precisamente incerto"'. Eis que finalmente tenho nomeado, através de um paradoxo (como poderia ser diferente?), o meu objeto de estudo.

E como bom paradoxo, no final somos devolvidos ao ponto de partida com o retorno do tema. "Coisas que são 'precisamente incertas' e que nos atravessam, as intensidades, as multiplicidades, não seriam a força de gênese, o tempo próprio do corpo, dos quais você fala em $A$ gênese de um corpo desconhecido?"

Você me evoca o problema "o tempo próprio do corpo".

Eu refleti recentemente de novo sobre o que é o gesto, os gestos. Deleuze fala em A imagem-tempo ${ }^{6}$ do "gestus" (termo proposto por Brecht). Nesse contexto, os gestos são quaisquer coisas que injetam o tempo no corpo. Uma vez que se começa a pensar o tempo, deve-se necessariamente pensar o tempo vivido pelo corpo, não somente pela mente, mas sobretudo pelo corpo.

Pensar o tempo nos incita a pensar o corpo no tempo, o que complica logo de saída todas as visões orgânicas do corpo espacializado.

Multiplicidade e intensidade são conceitos absolutamente necessários para elucidar esse tempo e esse corpo, não é? E isso não é tudo... Nós somos sempre obrigados a reinventar os termos e conceitos para exprimir e tornar sensiveis os aspectos sempre móveis desse tempo e desse corpo.

${ }^{6}$ Deleuze (2005). 
Relendo certos textos de Kafka e de Beckett, revejo a que ponto esses autores são atentos a todos os signos de diferenças captadas nos gestos, suas velocidades e lentidões, suas pequenas flexões, coagulações, hesitações, rachaduras e dobras, impossibilidade de fazer e dizer o que quer que seja, em suma, falhamos em tudo, não alcançamos nada de definitivo...

\section{Referências}

ARTAUD, A. O pesa-nervos. In: GUINSBURG, J. et al. (Org.). Linguagem e vida Antonin Artaud. São Paulo: Perspectiva, 1995. p. 209-212.

BARTHES, R. O império dos signos. São Paulo: Martins Fontes, 2007.

DELeUZE, G. Lógica do Sentido. São Paulo: Perspectiva, 1988.

DELEUZE, G. A imagem-tempo. São Paulo: Brasiliense, 2005. Coleção: Cinema, v. 2.

DELEUZE, G. Francis Bacon: lógica da sensação. Rio de Janeiro, J. Zahar, 2007.

DELEUZE, G.; GUATTARI, F. Mil platôs: capitalismo e esquizofrenia. São Paulo: Editora 34, 1995a. v. 1.

DELEUZE, G.; GUATTARI, F. Mil platôs: capitalismo e esquizofrenia. São Paulo: Editora 34, 1995b. v. 2.

DELEUZE, G.; GUATTARI, F. Mil platôs: capitalismo e esquizofrenia. São Paulo: Editora 34, 1996. v. 3.

DELEUZE, G.; GUATTARI, F. Mil platôs: capitalismo e esquizofrenia. São Paulo: Editora 34, 1997a. v. 4.

DELEUZE, G.; GUATTARI, F. Mil platôs: capitalismo e esquizofrenia. São Paulo: Editora 34, 1997b. v. 5.

DELEUZE, G.; GUATTARI, F. O Anti-Édipo: capitalismo e esquizofrenia. São Paulo: Editora 34, 2010.

PASSOS, E.; BARROS, R. B. A construção do plano da clínica e o conceito de transdisciplinaridade. Psicologia: Teoria e Pesquisa, Brasília, v. 16, n. 1, p. 71-79, jan./abr. 2000. Cross ${ }^{\text {Ref. }}$

PASSOS, E.; BARROS, R. B. Complexidade, transdisciplinaridade e produção de subjetividade. In: FONSECA, T. M. G.; KIRST. P. G. (Org.). Cartografias $e$ devires: a construção do presente. Porto Alegre, 2003. p. 81-89.

RAUTER, C. Clínica do esquecimento. Rio de Janeiro: EDUFF, 2013.

UNO, K. A gênese de um corpo desconhecido. São Paulo: n-1, 2012.

UNO, K. Guattari confrontações: conversas com Kuniichi Uno e Laymert Garcia dos Santos. São Paulo: n-1, 2016.

Recebido em: 19 de agosto de 2017 Aceito em: 25 de agosto de 2017 